\title{
Avaliação do óleo essencial de alecrim (Rosmarinus officinalis L.) como modulador da resistência bacteriana
}

\section{Evaluation of the rosemary essential oil (Rosmarinus officinalis L.) as modulator of bacterial resistance}

\author{
Daniele Silva Ribeiro ${ }^{1 *}$; Daniela Benevides Melo $^{1}$; \\ Alaíse Gil Guimarães²; Eudes Silva Velozo ${ }^{3}$
}

\begin{abstract}
Resumo
Diversos microrganismos podem ser veiculados por alimentos causando doenças nos seres humanos. Os antibióticos comumente utilizados no tratamento dessas doenças têm apresentado baixo ou nenhum efeito, tendo em vista à resistência que muitos microrganismos têm adquirido. Diante deste quadro, o objetivo desta pesquisa foi avaliar o óleo essencial das folhas de Rosmarinus officinalis L. como modulador da resistência bacteriana a drogas. O óleo essencial foi obtido através de hidrodestilação em aparelho de Clevenger por $3 \mathrm{~h}$. Foram testadas 4 cepas de E.coli resistentes a Ampicilina (AMP) e a Tetraciclina (TET) e 4 cepas de Salmonella spp. resistentes a Nitrofurantoína (NIT). As cepas em suspensão escala MacFarland 0,5 foram inoculadas em agar Mueller Hinton, em seguida os discos dos antibióticos embebidos com 10 e $20 \mu \mathrm{L}$ do óleo de alecrim puro foram dispostos sobre as placas. Após $24 \mathrm{~h} / 37^{\circ} \mathrm{C}$ foram medidos os halos ao redor dos discos. Todas as cepas avaliadas apresentaram susceptibilidade à ação combinada do óleo essencial com os antibióticos testados. Os resultados obtidos indicam ser promissora a utilização de óleo essencial de alecrim em associação com antibióticos no combate a bactérias patogênicas.
\end{abstract}

Palavras-chave: Óleo essencial, alecrim, resistência bacteriana

\begin{abstract}
Microorganisms can be transmitted by food causing diseases in humans. The antibiotics commonly used in treatment of these diseases have shown little or no effect, and in view of the resistance that many microorganisms have acquired. This study evaluated the essential oil leaves of Rosmarinus officinalis L. as a modulator of resistance bacterial drug. The essential oil was obtained by hydrodistillation in a Clevenger apparatus for 3 hours. We tested four strains of E.coli resistant ampicillin (AMP) and tetracycline (TET) and four strains of Salmonella spp. Resistant to nitrofurantoin (NIT). The strains in 0.5 MacFarland scale suspension were inoculated on Mueller Hinton agar, then soaked antibiotic disks with 10 and $20 \mu \mathrm{L}$ oil pure rosemary were placed on the plates. After $24 \mathrm{~h} / 37^{\circ} \mathrm{C}$ were measured halos around the discs. All strains tested showed susceptibility to the combined action of essential oil with antibiotics tested. The results indicate that the use of promising rosemary essential oil in combination with antibiotics to combat pathogenic bacteria.
\end{abstract}

Key words: Essential oil, rosemary, bacterial resistance

\footnotetext{
${ }^{1}$ Discente, Programa de Pós-Graduação em Ciência de Alimentos, Faculdade de Farmácia, Universidade Federal da Bahia, UFBA. Salvador, BA. E-mail: ribeirodanieles@gmail.com; danielabenevides@yahoo.com.br

${ }^{2}$ Prof $^{\mathrm{a}}$ Dr $^{\mathrm{a}}$ Dept $^{\mathrm{o}}$ de Análises Bromatologicas, Faculdade de Farmácia, UFBA. Salvador, BA. E-mail: alaise@ufba.br

${ }^{3}$ Prof. Dr. Dept ${ }^{\circ}$ de Medicamentos, Faculdade de Farmácia, UFBA. Salvador, BA. E-mail: euvelozo@ufba.br

* Autor para correspondência
} 


\section{Introdução}

Durante anos, as doenças transmitidas por alimentos resultantes do consumo dealimentoscontaminadoscombactériaspatogênicas e /ou suas toxinas, tem sido de vital importância para a saúde pública (KIM; MARSHALL; WEI, 1995). Atrelado a este fato, também é crescente o aparecimento de microrganismos resistentes aos antibióticos, devido ao seu uso extensivo em práticas terapêuticas em humanos e como promotores de crescimento e tratamento de doenças infecciosas em animais (BARTON, 2000; WHITE et al., 2002; SENGELOV et al., 2003). Tal situação aumentou o interesse no uso de compostos antimicrobianos naturais tais como extratos de especiarias e ervas para a conservação de alimentos (SHAN et al., 2007).

Muitas plantas têm sido utilizadas em razão de suas características antimicrobianas, devido aos compostos sintetizados no metabolismo secundário das mesmas. Estes produtos são conhecidos por suas substâncias ativas, como, por exemplo, compostos fenólicos que estão presentes no óleo essencial (JANSEN; CHEFFER; SVENDSEN, 1987).

Os óleos essenciais são responsáveis por conferir aroma e sabor característico às plantas e estão relacionados à atração de polinizadores, proteção contra insetos e de diversas funções necessárias à sobrevivência da planta (LIMA et al., 2003; SANTOS et al., 2004), eles apresentam composição complexa, sendo os terpenos considerados a classe de substâncias mais encontrada nas plantas (SANTOS et al., 2004).

O alecrim, Rosmarinus officinalis, é uma planta da família Lamiaceae. É utilizado mundialmente como condimento de inúmeros alimentos e possui várias indicações farmacêuticas (CARVALHO JUNIOR, 2004). Seu óleo essencial é constituído por hidrocarbonetos monoterpênicos, ésteres terpênicos, linalol, verbinol, terpineol, 3- octanona e acetato de isobornila, dentre outros compostos (ALONSO JUNIOR, 1998). A composição química pode apresentar variação devido a fatores ambientais e de manejo das plantas bem como da forma de extração e armazenamento, interferindo em sua atividade antimicrobiana (NASCIMENTO et al., 2007).

Bactérias provenientes de animais destinados à alimentação freqüentemente possuem resistência a uma gama de agentes antimicrobianos comumente utilizados em seres humanos e é possível que estes organismos resistentes possam ser transferidos para o homem, quer diretamente através da cadeia alimentar ou indiretamente como resultado da propagação de resíduos animais nos campos (GHOSH; LaPARA, 2007; HAMMERUM; HEUER, 2009).

A Escherichia coli faz parte da microflora intestinal da maioria dos animais e dos seres humanos e é comumente associado com as infecções não complicadas. Muitos relatórios têm demonstrado que a E.coli tem uma tendência a ser resistente a uma série de antibióticos (PAULA; MARIN, 2008).

O surgimento de cepas resistentes de Salmonella spp. é comum e este fato é agravado com a ampla utilização de antibiótico em rações animais, o que tem contribuído para potencializar a distribuição de Salmonella spp. resistentes presentes nas aves, havendo assim um risco maior nas doenças transmissíveis por alimentos em humanos causadas por estas bactérias (REIS; KRUGER; MACIEL, 1995).

No Brasil, Salmonella Enteritidis tem sido um dos mais prevalentes sorovares isolados em infecções humanas (CASTRO et al., 2002), bem como em fontes não-humanos, como meio ambiente, água, alimentos, animais, principalmente aves, e outras fontes desconhecidas (TAVECHIO et al., 2002).

O desenvolvimento de resistência antimicrobiana em bactérias zoonóticas (a exemplo da Salmonella spp. e E.coli), constitui um risco para a saúde pública, pois podem afetar a eficácia do tratamento da droga em seres humanos (AARESTRUP, 1999). A utilização de agentes antimicrobianos naturais 
como óleos essenciais de plantas, têm demonstrado ser uma alternativa eficaz no controle de bactérias resistentes a antibióticos, seja na inibição ou modulação das mesmas. Diante deste cenário a presente pesquisa teve por objetivo avaliar o potencial modulador do óleo essencial das folhas de alecrim (Rosmarinus officinalis L.) frente a cepas resistentes a antibióticos de E.coli e Salmonella spp. isoladas de alimentos.

\section{Materiais e Métodos}

Obtenção do material vegetal e extração do óleo essencial

Foram coletadas $395 \mathrm{~g}$ de folhas frescas de alecrim (Rosmarinus officinalis L.) na cidade de Boa Vista do Tupim (BA) em julho de 2009, sendo encaminhadas para o Herbário Alexandre Leal Costa do Instituto de Biologia da UFBA onde foi identificada botanicamente e catalogada com o número de exsicata 95954. O óleo essencial foi extraído através de hidrodestilação em aparelho de Clevenger por 3 horas (FARMACOPÉIA, 2000), no Laboratório de Pesquisa em Matéria Médica LAPEMM da Faculdade de Farmácia da UFBA. Em seguida, o óleo foi recolhido ( $4 \mathrm{~g}$ ) e armazenado em recipiente estéril sem a presença de luz a temperatura de $-10^{\circ} \mathrm{C}$ até o momento de uso.

\section{Caracterização do óleo essencial}

Cromatografia gasosa acoplada à espectrometria de massa (CG-EM): A análise qualitativa do óleo essencial foi realizada utilizando um cromatógrafo gasoso Shimadzu QP5050 equipado com coluna capilar de sílica fundida OV-5 (30 m; 0,25 mm;0,25 $\mu \mathrm{m})$ acoplado a espectrômetro de massa. O espectro de massa foi obtido com a voltagem de ionização de $70 \mathrm{eV}$ (temperatura da fonte $250{ }^{\circ} \mathrm{C}$ ). A rampa de temperatura foi programada de $40-180{ }^{\circ} \mathrm{C}$ a $4^{\circ}$ $\mathrm{C} / \mathrm{min}$ e de $180-280{ }^{\circ} \mathrm{C}$ a $20{ }^{\circ} \mathrm{C} / \mathrm{min}$ e mantido um isoterma por $7 \mathrm{~min}$. $\mathrm{O}$ gás de arraste utilizado foi o hélio com um fluxo de $1,0 \mathrm{~mL} / \mathrm{min}$.
A identificação dos compostos foi feita pela comparação de seus espectros de massa com o banco de dados do CG-EM (Wiley 229, Lib). Os dados quantitativos foram obtidos das percentagens das áreas do cromatograma através de normalização.

\section{Cepas testes}

Foram utilizadas 04 (quatro) cepas testes de Escherichia coli resistentes a ampicilina 10 microgramas/disco (AMP-10), tetraciclina 30 microgramas/disco (TET-30) e 4 (quatro) cepas de Salmonella spp. resistentes a nitrofurantoína 300 microgramas/disco (NIT-300). As cepas foram isoladas de diferentes alimentos no Laboratório de Pesquisa em Microbiologia de Alimentos da Faculdade de Farmácia, cultivadas por 24 horas em meio TSA (Trypticase Soy Agar) a $37^{\circ} \mathrm{C}$.

As suspensões das cepas foram realizadas em solução salina $(\mathrm{NaCl}$ a $0,85 \% \mathrm{p} / \mathrm{v})$, as quais foram padronizadas de acordo com o tubo 0,5 da escala McFarland correspondendo à concentração de aproximadamente $10^{8} \mathrm{UFC} / \mathrm{mL}$ (técnica adaptada de BAUER et al., 1966).

\section{Avaliação da Atividade Moduladora}

Os discos contendo os antibióticos (AMP-10, TET-30 e NIT-300) foram embebidos com $10 \mu \mathrm{L}$ e $20 \mu \mathrm{L}$ do óleo essencial de alecrim (OEA) bruto, em seguida, colocados em placas de Petri estéreis contendo ágar Muller-Hinton inoculado com as suspensões bacterianas descritas anteriormente, com o auxílio de "swabs" estéreis. Após incubação das placas a $37^{\circ} \mathrm{C}$ por 24 horas, foram observados os halos de inibição sobre as cepas bacterianas ensaiadas. Os resultados foram expressos em milímetros dos diâmetros dos halos formados ao redor dos discos (Adaptado de OLIVEIRA et. al., 2006).

A associação do OEA com os respectivos antibióticos foi considerada moduladora quando observada uma zona de inibição com diâmetro (mm) 
maior que a zona de inibição referente à resistência para cada antibiótico, conforme prescrição do fabricante, que considera Enterobactérias AMP resistente com halo de inibição de diâmetro $\leq$ $13 \mathrm{~mm}$, NIT $\leq 14 \mathrm{~mm}$ e TET $\leq 11 \mathrm{~mm}$.

\section{Resultados e Discussão}

O rendimento do óleo essencial obtido por hidrodestilação das folhas frescas de Rosmarinus officinalis L. foi de aproximadamente 1,0\% em relação ao peso do material fresco. Através de análise em CG-EM, dos 25 picos encontrados, foi possível identificar 23 componentes presentes no óleo essencial de alecrim analisado (Tabela 1). Os constituintes majoritários foram o $\alpha$-pineno (19,8\%), $\beta$-mirceno $(24,2 \%), 1,8$ cineol $(22,2 \%)$ e verbenona $(9,3 \%)$, correspondendo a $75,5 \%$ do total do óleo (Figura 1).

Figura 1. Estrutura química dos constituintes majoritários do óleo essencial de alecrim.

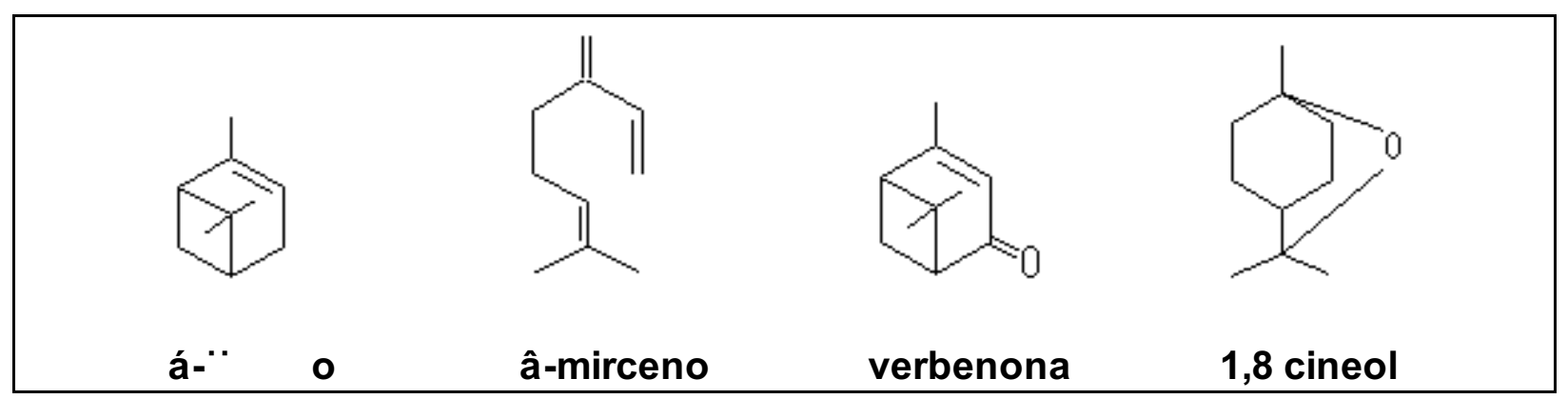

Fonte: Elaboração dos autores.

Resultados encontrados por Bauer, Garbe e Surburg (1997) e Tebaldi (2008) apontam o $\alpha$-pineno, 1,8 cineol e a cânfora como constituintes majoritários no óleo essencial de Rosmarinus officinalis L. Boix et al. (2010) encontraram como principais componentes, dos 25 compostos identificados, $\beta$-pineno (7,0\%), mirceno (9,52\%), 1,8 cineol $(14,02 \%)$, cânfora $(33,17 \%)$ e verbenona $(8,6 \%)$. Trabalho realizado por Prins, Kaatz e Gibbons (2006) traz a cânfora, 1,8 cineol, $\alpha$-pineno e $\beta$-mirceno, nessa ordem, como compostos em maior proporção no óleo, resultado semelhante ao encontrado neste trabalho. Atti-Santos et al. (2005) encontraram como principais componentes do óleo essencial de alecrim, $\alpha$-pineno $(40,55 \%$ a $45,10 \%)$ 1,8 cineol $(17,40 \%$ a $19,35 \%)$, canfeno (4,73 a $6,06 \%)$, verbenona $(2,32 \%$ a $3,86 \%)$ e borneol $(2,24 \%$ a $3,10 \%)$, resultado também encontrado por Santoyo et al. (2005), onde $80 \%$ do óleo de alecrim avaliado continha $\alpha$-pineno, 1,8 cineol, cânfora, verbenona e borneol. Gachkar et al.
(2007) observaram que os compostos majoritários da especiaria foram $\alpha$-pineno $(14,9 \%), 1,8$ cineol $(7,43 \%)$ e linalol (14,9\%). Svoboda e Deans (1992) atribuíram a atividade antibacteriana do alecrim aos compostos borneol, 1,8-cineol, pineno, canfeno e cânfora. Constituintes também presentes no óleo analisado.

Segundo Dellacassa et al. (1999) e Carvalho Junior (2004), variações significantes na composição química do óleo essencial de alecrim, dependem da região de cultivo, do método de extração utilizado, do método de análise, da parte da planta utilizada (folha ou planta inteira) e do preparo da matéria prima (in natura ou seca) para obtenção de seus extratos. O que explica os diferentes teores dos constituintes e a variação da composição, relatados em diversos estudos. Logo, é fundamental que a composição do óleo essencial seja precisamente conhecida, pois, sua composição pode variar de acordo com diversos fatores que podem alterar o teor do princípio ativo presente nele (NASCIMENTO et al., 2007). 
Tabela 1. Composição química do óleo essencial extraído das folhas de Rosmarinus officinalis L.

\begin{tabular}{cclc}
\hline Pico & TR & Compostos & $\%$ \\
\hline $\mathbf{1}$ & $\mathbf{8 . 4 1}$ & $\boldsymbol{\alpha}$-pineno & $\mathbf{1 9 , 8}$ \\
2 & 8.75 & canfeno & 2,8 \\
3 & 8.85 & n.i. & 0,4 \\
4 & 9.59 & $\beta$-pineno & 1,1 \\
5 & 9.87 & 5 -metil 3-heptanona & 1,7 \\
$\mathbf{6}$ & $\mathbf{1 0 . 5 1}$ & $\boldsymbol{\beta}$-mirceno & $\mathbf{2 4 , 2}$ \\
7 & 10.73 & 3-octanol & 1,3 \\
$\mathbf{8}$ & $\mathbf{1 1 . 8 4}$ & $\mathbf{1 , 8}$ cineol & $\mathbf{2 2 , 2}$ \\
9 & 12.61 & $\gamma$ terpineno & 0,4 \\
10 & 13.66 & $\alpha$-terpinoleno & 0,4 \\
11 & 14.89 & eucarvone & 0,5 \\
12 & 15.75 & cânfora & 3,8 \\
13 & 16.74 & $2,3,3$-trimetil-1,4-pentadieno & 2,0 \\
14 & 17.00 & terpineno-4-ol & 1,1 \\
15 & 17.89 & $\alpha$-terpineol & 2,5 \\
$\mathbf{1 6}$ & $\mathbf{1 8 . 4 1}$ & verbenona & $\mathbf{9 , 3}$ \\
17 & 20.86 & Acetato de bornila & 0,9 \\
18 & 25.60 & $\beta$-cariofileno & 2,3 \\
19 & 26.63 & $\alpha$-humuleno & 0,4 \\
20 & 30.65 & Oxido de cariofileno & 0,1 \\
21 & 35.82 & Nerolidol & 0,6 \\
22 & 36.27 & Linalol & 1,5 \\
23 & 38.32 & $\beta$-bisaboleno & 0,1 \\
24 & 38.52 & Farnesol & 0,2 \\
25 & 38.78 & n.i. & 0,5 \\
\hline & & &
\end{tabular}

TR: tempo de retenção; n.i.: composto não identificado.

Fonte: Elaboração dos autores.

Os resultados da Tabela 2 mostram que as cepas bacterianas de Salmonella spp. e E.coli foram susceptíveis à ação combinada dos antibióticos (AMP,NIT e TET) com o OEA, nas duas quantidades utilizadas. Tendo uma maior expressividade as cepas de Salmonella spp. que apresentaram halos de inibição maior ou igual $20 \mathrm{~mm}$. A cepa de E.coli
(EC17) resistente a AMP-10, apresentou um melhor efeito sinérgico utilizando $20 \mu \mathrm{L}$ do OEA sobre o disco de antibiótico, visto que o diâmetro do halo de inibição formado $(17 \mathrm{~mm})$ foi maior do que o diâmetro limite de resistência $(\leq 13 \mathrm{~mm})$ de atuação do antibiótico isoladamente. Evidenciando que uma maior quantidade do OEA aumentou a ação ampicilina frente a cepa avaliada. 
Tabela 2. Susceptibilidade de cepas bacterianas frente à ação combinada do OEA com antibióticos (resultados expressos em diâmetro dos halos de inibição do crescimento microbiano em $\mathrm{mm}$ ).

\begin{tabular}{|c|c|c|c|c|c|c|c|c|c|c|}
\hline \multicolumn{2}{|c|}{ Ensaios } & $\begin{array}{c}\mathrm{S} 4 \\
\text { (NIT) }\end{array}$ & $\begin{array}{c}\text { S5 } \\
\text { (NIT) }\end{array}$ & $\begin{array}{c}\mathrm{S} 8 \\
(\mathrm{NIT})\end{array}$ & $\begin{array}{c}\text { S9 } \\
\text { (NIT) }\end{array}$ & $\begin{array}{c}\text { EC17 } \\
\text { (AMP) }\end{array}$ & $\begin{array}{c}\text { EC17 } \\
\text { (TET) }\end{array}$ & $\begin{array}{c}\text { EC30 } \\
\text { (TET) }\end{array}$ & $\begin{array}{l}\text { EC15 } \\
\text { (TET) }\end{array}$ & $\begin{array}{l}\text { EC20 } \\
\text { (TET) }\end{array}$ \\
\hline \multirow{2}{*}{\multicolumn{2}{|c|}{ Antibiótico/Perfil }} & 11 & 16 & 11 & 16 & 0 & 0 & 0 & 0 & 7 \\
\hline & & $R$ & $I$ & $R$ & $I$ & $R$ & $R$ & $R$ & $R$ & $R$ \\
\hline \multirow{2}{*}{ 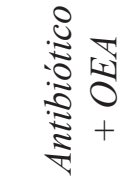 } & $10 \mu \mathrm{L}$ & 24 & 25 & 22 & 20 & 8 & 13 & 17 & 16 & 15 \\
\hline & $20 \mu \mathrm{L}$ & 25 & 28 & 23 & 22 & 17 & 17 & 20 & 21 & 18 \\
\hline
\end{tabular}

S: Salmonella spp. EC: Escherichia coli; AMP: ampicilina; NIT: nitrofurantoína; TET: tetraciclina; OEA: óleo essencial de alecrim; R: Resistente; I: Intermediário.

Fonte: Elaboração dos autores.

Em trabalho realizado por Zago et al. (2009) onde foi avaliado o efeito sinérgico entre o óleo essencial da Rosmarinus officinalis L. e cepas não resistentes de S.aureus e E.coli isoladas de humanos, foi verificado sinergismo entre o óleo e três drogas frente as cepas de $S$. aureus (Gentamicina, Tetraciclina e Sulfazotrim) e contra as cepas de E.coli (Cloranfenicol, Cefepime e Tetraciclina). Luqman et al. (2007) avaliaram potencial antimicrobiano do óleo com cepas clínicas Gram-positivas e Gram-negativas resistentes a drogas, obtendo uma maior atividade contra as bactérias Gram-positivas. Nascimento et al. (2000), utilizaram o extrato etanólico da planta, onde não foi verificado efeito sinérgico com os antibióticos contra as cepas estudadas.

De acordo com Harris (2003), bactérias Gramnegativas são mais resistentes aos antibióticos do que as bactérias Gram-positivas. Isso devido à presença de uma parede bacteriana que normalmente não restringe a penetração de moléculas tóxicas, enquanto as Gram negativas possuem um sistema de barreira constituído pela membrana externa da parede bacteriana formada por fosfolipídios, lipopolissacarídeos e proteínas (porinas) que conferem considerável impermeabilidade aos agentes antibacterianos, resultando em maior resistência dessas bactérias aos antibióticos (LAMBERT, 2002). Todavia, o óleo essencial de alecrim demonstrou neste estudo um efeito positivo contra as cepas Gramnegativas testadas. Isto devido à natureza lipídica dos compostos terpênicos presente no óleo que, segundo Harris (2003) e Zhao et al. (2001) permite um melhor transporte do antibiótico para dentro da célula bacteriana, alterando a permeabilidade da membrana citoplasmática.

Jarrar, Abu-Hijleh e Adwan (2010) avaliaram o uso de extrato etanólico de alecrim em combinação com cefuroxima frente a cepas de Staphylococcus aureus meticilina resistente (MRSA), indicando sinergismo contras todas as cepas MRSA avaliadas. De acordo com estes autores, o mecanismo que rege a ação conjunta de extrato de alecrim e componentes antibióticos é ainda desconhecido, que pode estar ligado ao grande número de diferentes grupos de compostos químicos presentes nos extratos de alecrim. Isto pode se estender também ao óleo essencial. Em outro estudo, van Vuuren, Suliman e Viljoen (2009) encontraram perfis antagônicos do óleo essencial comercial de alecrim em combinação com ciprofloxacina ou anfoteracina B contra cepas padrão de $S$. aureus e Candida albicans.

Em trabalho realizado por Oluwatuyi, Kaatz e Gibbons (2004) onde foram utilizados compostos presentes (ácido carnósico e carnosol) no extrato clorofórmico das folhas de Rosmarinus officinalis L. para modular a resistência de cepas de S.aureus 
multiressitentes, foi observado que esses compostos potencializaram a atividade do antibiótico eritromicina em 32 e 16 vezes, respectivamente, contra uma cepa portadora do mecanismo efluxo resistente a eritromicina. Demonstrando assim, o potencial antimicrobiano e modulador presente também no extrato das folhas do alecrim. Todavia, vale ressaltar que a técnica empregada na extração, dentre outros fatores, influencia diretamente na ação antimicrobiana (NASCIMENTO et al., 2007).

Trabalhos em que foram utilizados outros óleos essenciais e seus compostos isolados, como eugenol, timol, cavacrol entre outros (GALLUCCI et al., 2006; OLIVEIRA et al., 2006; HEMAISWARYA; DOBLE, 2009; PALANIAPPAN; HOLLEY, 2010) em combinação com drogas contra bactérias Grampositivas e Gram-negativas sensíveis e resistentes a antibióticos, mostraram resultados promissores, demonstrando que em uma época onde é crescente a resistência microbiana aos antibióticos sintéticos, há uma tendência para procurar maneiras de minimizar o desenvolvimento de resistência aos medicamentos existentes, no lugar de se buscar novas drogas mais potentes (HARRIS, 2003).

Embora diversos estudos relatem a atividade antimicrobiana da Rosmarinus officinalis L., (ANGIONI et al., 2004; OLUWATUYI; KAATZ; GIBBONS, 2004; BOZIN et al., 2007; LUQMAN et al., 2007; van VUUREN; SULIMAN; VILJOEN, 2009; ZAGO et al., 2009; JARRAR; ABU-HIJLEH; ADWAN, 2010) nenhum trabalho foi encontrado durante a pesquisa utilizando o óleo essencial da planta estudada, como modulador de bactérias isoladas de alimentos resistentes aos antibióticos convencionais.

Tendo em vista que os gêneros bacterianos testados estão comumente associados a doenças de origem alimentar, o resultado encontrado foi muito relevante para a pesquisa, mesmo não se tendo determinado a Concentração Inibitória Mínima (CIM) do óleo, pois, o mesmo mostrou potencial bioativo em modular as cepas resistentes de Salmonella spp. e E.coli estudadas.

\section{Conclusão}

Os resultados demonstraram que o óleo essencial de alecrim testado, possui como constituintes majoritários o $\alpha$-pineno $(19,8 \%), \quad \beta$-mirceno $(24,2 \%), 1,8$ cineol $(22,2 \%)$ e verbenona $(9,3 \%)$, conforme descrito na literatura. E que o mesmo foi eficaz em modular a resistência de cepas de E.coli e Salmonella spp., quando associado com os antibióticos ampicilina, tetraciclina e nitrofurantoína. Os resultados obtidos indicam ser promissora a utilização de óleo essencial de alecrim em associação com antibióticos convencionais no controle a bactérias potencialmente patogênicas de origem alimentar.

\section{Referências}

AARESTRUP, F. M. Association between the consumption of antimicrobial agents in animal husbandry and the occurrence of resistant bacteria among food animals. Int. J. Antimicrob. Agents, Birmingham-UK, v. 12, n. 4, p. 279-285, 1999.

ALONSO JUNIOR, R. Tratado de fitomedicina: bases clínicas y farmacológicas. Buenos Aires: Isis Ediciones. SRL, 1998. 1039 p.

ANGIONI, A.; BARRA, A.; CERETI, E.; BARILE, D.; COISSON, J. D.; ARLORIO, M.; DESSI, S.; CORONEO, V.; CABRAS, P. Chemical composition, plant genetic differences, antimicrobial and antifungal activity investigation of the essential oil of Rosmarinus officinalis L. J Agric. Food Chem., Washington, v. 52, n. 11, p. 3530-3532, 2004.

ATTI-SANTOS, A. C.; ROSSATO, M.; PAULETTI, G. F.; ROTA, L. D.; RECH, J. C.; PANSERA, M. R.; AGOSTINI, F.; SERAFINI, L. A.; MOYNA, P. Physicochemical evaluation of Rosmarinus officinalis L. essential oils. Brazilian Archives of Biology and Technology, Curitiba, v. 48, n. 6, p. 1035-1039, 2005.

BARTON, D. M. Antibiotic use in animal feed and its impact on human health. Nutrition Research Reviews, Cambridge, v. 13, n. 2, p. 279-299, 2000.

BAUER, A. W.; KIRBY, W. M. M.; SHERRIS, J. C.; TURCK, M. Antibiotic susceptibility testing by a standardized single disk method. American Journal of Clinical Pathology, Washington, v. 45, n. 4, p. 493-496, 1966. 
BAUER, K.; GARBE, D.; SURBURG, H. Common fragrance and flavor materials: preparation, properties and uses. 3. ed. Germany: Wiley-VCH, 1997.

BOIX, Y. F.; VICTÓRIO, C. P.; LAGE, C. L. S.; KUSTER, R. M. Volatile compounds from Rosmarinus officinalis L. and Baccharis dracunculifolia DC. Growing in southeast coast of Brazil. Química Nova, São Paulo, v. 33, n. 2, p. 255-257, 2010.

BOZIN, B.; MIMICA-DUKIC, N.; SAMOJLIK, I.; JOVIN, E. Antimicrobial and antioxidant properties of rosemary and sage (Rosmarinus officinalis L. and Salvia officinalis L., Lamiaceae) essential oils. J Agric Food Chem., Washington, v. 55, n. 19, p. 7879-7885, 2007.

CARVALHO JUNIOR, R. N. Obtenção de extrato de alecrim (Rosmarinus officinalis) por extração supercrítica: determinação do rendimento global, de parâmetros cinéticos e de equilíbrio e outras variáveis do processo. 2004. Tese (Doutorado em Engenharia de Alimentos) - Faculdade de Engenharia de Alimentos. Universidade Estadual de Campinas, Campinas.

CASTRO, F. A.; SANTOS, V. R.; MARTINS, C. H. G.; FERNANDEZ, S. A.; ZAIA, J. E.; MARTINEZ, R. Prevalence and antimicrobial susceptibility of salmonella serotypes in patients from Ribeirão Preto, São Paulo, Brazil, between 1985 and 1999. Braz. J. Infec. Dis., Salvador, v. 6, n. 5, p. 244-251, 2002.

DELLACASSA, E.; LORENZO, D.; MOYNA, P.; FRIZZO, C. D.; ATTI-SERAFINI, L.; DUGO, P. Rosmarinus officinalis L. (Labiatae) essential oils from the South of Brazil and Uruguay. Journal of Essential Oils Research, London, v. 11, n. 1, p. 27-30, 1999.

FARMACOPÉIA brasileira. 4. ed. parte II. São Paulo: Atheneu, 2000.

GACHKAR, L.; YADEGARI, D.; REZAEI, M. B.; TAGHIZADEH, M.; ASTANEH, S. A.; RASOOLI, I. Chemical and biological characteristics of Cuminum cyminum and Rosmarinus officinalis essential oils. Food Chemistry, UK, v. 102, n. 3, p. 898-904, 2007.

GALLUCCI, N.; CASERO, C.; OLIVA, M.; ZYGADLO, J.; DEMO, M. Interaction between terpenes and penicillin on bacterial strains resistant to beta-lactam antibiotics. Mol. Med. Chem., Argentina, v. 10, n. 1, p. 30-32, 2006.

GHOSH, S.; LaPARA, T. M. The effect of subtherapeutic antibiotic use in farm animals on the proliferation and persistence of antibiotic resistance among soil bacteria. The International Society for Microbial Ecology Journal, The Netherlands, v. 1, n. 1, p. 191-203, 2007.

HAMMERUM, A. M.; HEUER, O. E. Human health hazards from antimicrobial resistant Escherichia coli of animal origin. Clinical Infectious Diseases, Oxford, v. 48, n. 7, p. 916-921, 2009.

HARRIS, R. Sinergism in the essential oil world. The International Journal of Aromatherapy, Reino Unido, v. 12, n. 4, p. 179-186, 2003.

HEMAISWARYA, S.; DOBLE, M. Synergistic interaction of eugenol with antibiotics against Gram negative bacteria. Phytomedicine, Germany, v. 16, n. 11, p. 997-1005, 2009.

JANSEN, A. M.; CHEFFER, J. J. C.; SVENDSEN, A. B. Antimicrobial activity of essencial oils: a 1976-1986 literature review. Aspects of test methods. Planta Med., New York, v. 53, n. 5, p. 395-398, 1987.

JARRAR, N.; ABU-HIJLEH, A.; ADWAN, K. Antibacterial activity of Rosmarinus officinalis L., alone and in combination with cefuroxime, against methicillinresistant Staphylococcus aureus. Asian Pacific Journal of Tropical Medicine, China, v. 3, n. 2, p. 121-123, 2010.

KIM, J.; MARSHALL, M. R.; WEI, C.-I. Antibacterial activity of some essential oil components against five foodborne pathogens. Journal of Agricultural and Food Chemistry, Washington, v. 43, n. 11, p. 2839-2845, 1995.

LAMBERT, P. A. Cellular impermeability and uptake of biocides and antibiotics in gram positive bactéria and mycobacteria. J. Appl. Microbiol., Bedford-UK, v. 92, p. 46S-54, 2002. Supplement 1.

LIMA, E. O.; FARIAS, N. M. P.; SOUZA, E. L.; SANTOS, B. H. C. Propriedades antibacterianas de óleos essenciais de plantas medicinais. Rev Bras Cienc Saude, João Pessoa, v. 7, n. 3, p. 251-258, 2003.

LUQMAN, S.; DWIVEDI, G. R.; DAROKAR, M. P.; KALRA, A.; KHANUJA, S. P. Potential of rosemary oil to be used in drug-resistant infections. Altern Ther Health Med, St Paul-Minnesota, v. 13, n. 5, p. 54-59, 2007.

NASCIMENTO, P. F. C.; NASCIMENTO, A. C.; RODRIGUES, C. S.; ANTONIOLLI, A. A.; SANTOS, P. O.; BARBOSA JUNIOR, A. M.; TRINDADE, R. C. Antimicrobial activity of the essentials oils: a multifactor approach of the methods. Rev. Bras. Farmacogn., João Pessoa, v. 17, n. 1, p. 108-113, 2007.

NASCIMENTO, G. G. F.; LOCATELLI, J.; FREITAS, P. C.; SILVA, G. L. E. Antibacterial activiy of plant extracts and phytochemical on antibiotic-resistant bacteria. Brazilian Journal of Microbiology, São Paulo, v. 31, n. 4, p. $247-256,2000$.

OLIVEIRA, R. A. G.; LIMA, E. O.; VIEIRA, W. L.; FREIRE, K. R. L.; TRAJANO, V. N.; LIMA, I. O.; SOUZA, E. L.; TOLEDO, M. S.; SILVA-FILHO, R. 
N. Estudo da interferência de óleos essenciais sobre a atividade de alguns antibióticos usados na clínica. Rev. Bras. Farmacogn., João Pessoa, v. 16, n. 1, p. 82-77, 2006.

OLUWATUYI, M.; KAATZ, G. W.; GIBBONS, S. Antibacterial and resistance modifying activity of Rosmarinus officinalis. Phytochemistry, UK, v. 65, n. 24, p. 3249-3254, 2004.

PALANIAPPAN, K.; HOLLEY, R. A. Use of natural antimicrobials to increase antibiotic susceptibility of drug resistant bacteria. International Journal of Food Microbiology, Rome, v. 140, n. 2-3, p. 164-168, 2010.

PAULA, C. J. S. de; MARIN, J. M. Isolation of extraintestinal pathogenic Escherichia coli from diarrheic dogs and their antimicrobial resistance profile. Braz. J. Microbiol., São Paulo, v. 39, n. 3, p. 498-500, 2008.

PRINS, C. L.; LEMOS, C .S. L.; FREITAS, S. P. Efeito do tempo de extração sobre a composição e o rendimento do óleo essencial de alecrim (Rosmarinus Officinalis). Revista Brasileira de Plantas Medicinais, Botucatu, v. 8, n. 4, p. 92-95, 2006. Disponível em: <http://www.ibb. unesp.br/servicos/publicacoes/rbpm/ pdf_v8_n4_2006/ artigo17_v8_n4_p092-095.pdf $>$. Acesso em: 25 jun. 2010 .

REIS, R. B.; KRUGER, C. S.; MACIEL, M. S. Salmonella spp. em produtos cárneos comercializados no município de Cuiabá-MT. Avaliação da metodologia de pesquisa. Modelos de resistência a drogas antimicrobianas. Ciência e Tecnologia, São Paulo, v. 15, n. 1, p. 74-78, 1995.

SANTOS, A. S.; ALVES, S. M.; FIGUEIREDO, F. J. C.; ROCHA NETO, O. G. Descrição de sistema e métodos de extração de óleos essenciais e determinação de umidade de biomassa em laboratório. Comunicado Técnico-Embrapa, Belém, v. 99, n. 1, p. 1-6, 2004.

SANTOYO, S.; CAVERO, S.; JAIME, L.; IBANEZ, E.; SENORANS, F. J.; REGLERO, G. Chemical composition and antimicrobial activity of Rosmarinus officinalis L. essential oil obtained via supercritical fluid extraction. Journal of Food Protection, Iowa-USA, v. 68, n. 4, p. 790-795, 2005.

SENGELOV, G.; AGERSO, Y.; HALLINGSORENSEN, B.; BALODA, B. S.; ANDERSEN, J. S.; JENSEN, L. B. Bacterial antibiotic resistance levels in
Danish farmland as a result of treatment with pig manure slurry. Environment International, UK, v. 28, n. 7, p. 587-595, 2003.

SHAN, B.; CAI, Yi-Z.; BROOKS, J. D.; CORKE, H. The in vitro antibacterial activity of dietary spice and medicinal herb extracts. International Journal of Food Microbiology, Rome, v. 117, n. 1, p. 112-119, 2007.

SVOBODA, K. P.; DEANS, S. G. A study of the variability of rosemary and sage and their volatile oils on the British market: their antioxidative properties. Flavour and Flagrance Journal, UK, v. 7, n. 2, p. 81-87, apr. 1992.

TAVECHIO, A. T.; GHILARDI, A. C. R.; PERESI, J. T. M.; FUZIHARA, T. O.; YONAMINE, E. K.; JAKABI, M.; FERNANDEZ, S. A. Salmonella serotypes isolated from non human sources in São Paulo, Brazil, from 1996 through 2000. J. Food Protec., Iowa-USA, v. 65, n. 6, p. 1041-1044, 2002.

TEBALDI, V. M. R. Análise e potencial de uso de óleos essenciais no controle de Pseudomonas sp. e na formação de biofilme por Pseudomonas aeruginosa. 2008. Tese (Doutorado em Ciência dos Alimentos) - Universidade Federal de Lavras, Lavras.

Van VUUREN, S. F.; SULIMAN, S.; VILJOEN, A. M. The antimicrobial activity of four commercial essentials oils in combination with conventional antimicrobials. Lett Appl. Microbiol., Bedford-UK, v. 48, n. 4, p. 440446, 2009.

WHITE, D. G.; ZHAO, S.; SIMJEE, S.; WAGENR, D. D.; McDERMOTT, P. F. Antimicrobial resistance of foodborne pathogens. Microbes and Infection, France, v. 4, n. 4, p. 405-412, 2002.

ZAGO, J. A. A.; USHIMARU, P. I.; BARBOSA, L. N.; FERNANDES JUNIOR, A. Synergism between essential oils and antimicrobial drugs against Staphylooccus aureus and Escherichia coli strains from human infections. Rev. Bras. Farmacogn., João Pessoa, v. 19, n. 4, p. 828-833, dec. 2009.

ZHAO, W. H.; HU, Z. Q.; OKUBO, S.; HARA, Y.; SHIMAMURA, T. Mechanism of synergy between epigallocatechin gallate and beta-lactams against methicillin-resistant Staphylococcus aureus. Antimicrob Agents Chemothe, Washington, v. 45, n. 6, p. 1737-1742, 2001. 
